\title{
Representing infant feeding: content analysis of British media portrayals of bottle feeding and breast feeding
}

\author{
Lesley Henderson, Jenny Kitzinger, Josephine Green
}

\begin{abstract}
Centre for Media
and

Communications

Research,

Department of

Human Sciences,

Brunel University,

London UB8 3PH

Lesley Henderson

senior research fellow

Jenny Kitzinger

reader

Mother and Infant Research Unit,

University of Leeds,

Leeds LS2 9LN

Josephine Green

senior lecturer

Correspondence to:

L Henderson

lesley.henderson@

brunel.ac.uk
\end{abstract}

BMJ 2000;321:1196-8

\begin{abstract}
Objective To examine how breast feeding and bottle feeding are represented by the British media.

Design Content analysis.

Subjects Television programmes and newspaper

articles that made reference to infant feeding during March 1999.

Setting UK mass media.

Main outcome measures Visual and verbal

references to breast or bottle feeding in newspapers and television programmes.

Results Overall, 235 references to infant feeding were identified in the television sample and 38 in the newspaper sample. Bottle feeding was shown more often than breast feeding and was presented as less problematic. Bottle feeding was associated with "ordinary" families whereas breast feeding was associated with middle class or celebrity women. The health risks of formula milk and the health benefits of breast feeding were rarely mentioned.

Conclusions The media rarely present positive information on breast feeding, even though this feeding practice is associated with the most health benefits. Health professionals and policy makers should be aware of patterns in media coverage and the cultural background within which women make decisions about infant feeding.
\end{abstract}

\section{Introduction}

The mass media have a powerful impact on public perceptions of health issues. ${ }^{1}$ Headline health scares have a measurable effect on behaviour, and routine coverage influences people's assessments of personal risk, utilisation of health services, and views on public policy. ${ }^{2-7}$ The media not only provide information but also help to create or reinforce ideas about what is common sense or normal.

Breast feeding confers crucial health benefits on both the mother and the infant..$^{8-12}$ The prevalence of breast feeding in the United Kingdom, however, is among the lowest in Europe. Breast feeding is also less prevalent within certain socioeconomic groups, thus compounding existing health inequalities. Sociocultural factors are assumed to play a part in women's decision making about feeding infants ${ }^{13}{ }^{14}$; however, there is a lack of research into how breast and bottle feeding are culturally represented. Our study was designed to fill this gap. We systematically analysed during one month the portrayal of bottle and breast feeding by British newspapers and television. This was the first of a two part study examining how the media represent infant feeding and thus might influence women's choices.

\section{Methods}

\section{Samples}

March 1999 was prospectively chosen for analysis. This was a month during which there were no special initiatives or major news stories about infant feeding.

Press sample-We analysed 13 national British newspapers. These included tabloid, broadsheet, daily, and Sunday newspapers and reflected publications at different points on the political spectrum. We selected the Times, Daily Telegraph, Guardian, Daily Mail, Sun, Mirror, Observer, Mail on Sunday, Sunday Times, News of the World, the People, Sunday Telegraph, and Sunday Mirror. We read these every day during March and added to our database any reference to breast or bottle feeding in the headline, main text, or accompanying visual image.

Television sample-To maximise the possibility of locating references to infant feeding in a variety of programme types, we sampled television programmes on the basis of two criteria. Firstly, we recorded all regular health and parenting series broadcast during that month, and we monitored the listings in the Radio Times to identify any additional programmes that addressed issues of health, medicine, parenting, or infants. We recorded these programmes on the grounds that they were the ones most likely to feature infant feeding. Secondly, we recorded a selection of programmes to reflect a variety of types: news bulletins, soap operas, medical drama series, and daytime non-fiction programmes. Our selection criteria involved preselecting named examples of such programmes then recording and viewing all episodes or bulletins for the month. We also recorded and analysed all advertisements shown within the selected programmes.

\section{Coding and analysis}

We quantitatively analysed the media sample by using a computerised coding frame, designed to establish the overall frequency with which breast or bottle feeding was portrayed and to identify where these representations occurred. Every explicit reference to breast or bottle feeding within the sample was coded for feeding method (breast or bottle), type of reference (visual or verbal), and the type of programme in which it appeared. We also coded each item to record whether any problems were associated with the feeding method, what these problems were, and whether any solutions were proposed.

The qualitative analysis was designed to explore the overall context and narrative in which the practice of infant feeding occurred. We therefore examined how the mother was characterised (for example, noting any signifiers of social class), and the language and imagery associated with each feeding practice.

\section{Results}

Within the television sample, we identified 235 visual or verbal references to breast or bottle feeding. These 
were identified most often in health and parenting programmes, followed by medical dramas and soap operas, daytime non-fiction programmes, intermission advertisements, and news and documentary programmes (table 1).

In the press sample, we identified 38 references to breast or bottle feeding in 37 different newspaper editions. Most appeared in the daily tabloids (19 references). A further 10 references occurred in the daily broadsheets, six in the Sunday broadsheets, and three in the Sunday tabloids.

\section{Representations of infant feeding on television}

Analysis of television coverage of infant feeding highlighted striking patterns and major omissions (table 2). Firstly, breast feeding was rarely shown. We identified just one scene, showing a baby being put to the breast (Brookside, Channel 4, 13 March), with a further nine scenes involving a breast pump (not in use). The preparation of formula milk and bottle feeding appeared in 170 scenes. Secondly, most references to breast feeding were verbal (outweighing visual references by $3: 1$ ), whereas most references to bottle feeding were visual (outweighing verbal references by 7:1). A baby might be bottle fed in a background scene on television, but breast feeding was usually subject to remark. Thirdly, breast feeding was most often portrayed within fictional genres compared with other programme types. It featured as a running story line in three soap operas during the sampling period (EastEnders, BBC1, Coronation Street, ITV, and Brookside, Channel 4).

Our qualitative analysis showed that, within fictional genres, breast feeding not only provided a social issue story line but also provided humour around the themes of the "out of control" body, embarrassment, and the sexuality of breasts. For example, in an episode of Coronation Street (14 March) a barmaid (whose breasts had been leaking) asked a startled male customer whether he could see that her bra was stuffed with toilet paper. Fourthly, bottle feeding, unlike breast feeding, featured in all of the programme genres. In particular, the depiction of bottle feeding in advertisements signified positive male involvement in parenthood. Images of men preparing formula milk and bottle feeding infants were shown in two advertisements (one for whisky and one for digital television packages). Finally, references to breast feeding frequently highlighted potential problems, whereas difficulties with bottle feeding were rarely mentioned. The television sample included only one reference to potential bottle feeding difficulties (the time consuming practice of sterilising bottles, Liverpool Mums, Channel 5, 15 March). In contrast, there were 27 references to breastfeeding problems, including mastitis, engorged breasts, sore nipples, and the practical and emotional difficulties of leaving a breastfed infant ( $L i v$ erpool Mums, 11 March, ER, Channel 4, 17 March, This Morning, ITV, 18 March, and Brookside, 13 March).

Throughout the television coverage there was only one, oblique, reference to the potential health risks of bottle feeding (a paediatrician asked whether a sick infant was receiving formula milk, implying that it could be a factor in the illness; ER, 17 March). No explicit references were made to the health benefits of breast feeding.

\begin{tabular}{|c|c|c|c|c|c|}
\hline \multirow[b]{2}{*}{ Programme type } & \multicolumn{2}{|c|}{ Programme episodes } & \multicolumn{3}{|c|}{ References to infant feeding* } \\
\hline & Analysed & $\begin{array}{l}\text { With infant } \\
\text { feeding }\end{array}$ & Bottle & Breast & Total \\
\hline Health or parenting & 26 & 23 & 142 & 2 & 144 \\
\hline Medical drama or soap opera & 64 & 8 & 39 & 29 & 68 \\
\hline News or documentary & 37 & 1 & 1 & 0 & 1 \\
\hline Daytime non-fiction & 23 & 3 & 9 & 10 & 19 \\
\hline Intermission advertisements & 1246 & 2 & 3 & 0 & 3 \\
\hline Total & 1396 & 37 & 194 & 41 & 235 \\
\hline
\end{tabular}

*Visual or verbal, or both.

\section{Representations of infant feeding by the press}

Most references to breast feeding in the press sample (35 of 38) were simply cursory comments made within reports, columns, or feature articles about other issues. Most of the references (15 of 35) related to problems, and most of these (9 of 15) provided no suggestions of how the problems might be resolved. Breast feeding was described as reducing a woman to "meals on heels" (Daily Telegraph, 13 March) and was blamed for disrupted sleep, painful nipples, weight gain, and saggy breasts. In contrast, there were no references to any potential difficulties with bottle feeding.

Three descriptions of breast feeding as a wholly positive experience did, however, appear. For example, one woman commented "I was back at work within a month of having Ruby. I took her on set and was able to breast-feed her and have her with me all the time" (Daily Mail, 1 March). In all three cases the positive experiences were linked to the mothers' autonomous working conditions, but this was not explored in the article. Breast feeding was, however, used as a signifier of social class. For example, one feature on designer merchandise for babies mentioned that "if they throw up down the front of their Agnès B babygro, it's only handmashed organic vegetables or breast milk as giltedged as their parents' credit rating" (Guardian, 29 March).

We found no visual images of breast feeding, whereas an article on sperm donation was illustrated by a baby feeding from a bottle (Sun, 19 March). The image represented babies in general rather than a particular aspect of infant feeding. It seems that bottle feeding has become symbolic of babyhood itself.

We found only one reference to the potential health risks of formula milk, concerning genetically modified ingredients in a particular brand (Daily Mail, $11 \mathrm{March})$. In contrast, two items noted in passing that drugs might be transferred to the baby through breast milk, and one newspaper reported on a breastfed baby who starved to death. This last item quoted an expert on "breast milk insufficiency syndrome" who stated "it could happen to anybody" (Guardian, 16 March). In the

Table 2 Number of visual and verbal references to breast and bottle feeding in different programme types

\begin{tabular}{lcccccc} 
& \multicolumn{2}{c}{ References to breast feeding } & & \multicolumn{2}{c}{ References to bottle feeding } \\
\cline { 2 - 3 } \cline { 6 - 6 } Programme type & Visual & Verbal & & Visual & Verbal \\
\hline Health or parenting & 0 & 2 & & 127 & 15 \\
\hline Medical drama or soap opera & 10 & 19 & & 30 & 9 \\
\hline News or documentary & 0 & 0 & & 1 & 9 \\
\hline Daytime non-fiction & 0 & 10 & & 3 & 0 \\
\hline Intermission advertisements & 10 & 31 & & 170 & 0 \\
\hline Total & & 0 & 0 & \\
\hline
\end{tabular}




\section{What is already known on this topic}

Sociocultural factors are believed to play a part in women's decisions making about infant feeding

No previous study has examined how infant feeding is portrayed in the British media

\section{What this study adds}

Breast and bottle feeding are portrayed very differently by the mass media

Bottle feeding is shown more often than breast feeding and is presented as being less problematic

Bottle feeding is associated with "ordinary" families whereas breast feeding is associated with middle class or celebrity women

Health professionals and policy makers should be aware of patterns in media coverage and the cultural background within which women make decisions about infant feeding

entire press sample, we found no explicit references to the health benefits of breast feeding.

Media coverage implies that breast feeding is problematic, funny, and embarrassing, and that it is associated with middle class or celebrity women. In contrast, bottle feeding is socially integrated, highly visible, unproblematic, and associated with "ordinary" families. The health benefits of breast feeding and the risks of formula feeding were largely absent in routine media coverage.

\section{Discussion}

The mass media do not promote a positive image of breast feeding, even though it is the method of infant feeding associated with the most health benefits. Media coverage may, of course, reflect the reality of what is publicly visible- that is, that many women do not breast feed in public-and attention to problems may prepare women for the realities of breast feeding. These limited portrayals, however, may also help perpetuate a lack of acceptance of breast feeding in public. They may also sustain ideas that breast feeding is a difficult activity, likely to fail, or that it is an option only for certain types of women. Although some people argue that we live in a culture that makes breast feeding "compulsory," this does not seem to be the case as far as mass media representation is concerned. On the contrary, bottle feeding seems to be normalised and represented as the obvious choice.

We chose to analyse the coverage of infant feeding by the media for one month only, and it may be useful to compare the portrayal of breast and bottle feeding over a longer time frame. This would enable comparison between routine coverage and special initiatives (for example, breastfeeding awareness week). It may also be valuable to extend the sampling to include children's programming to explore messages reaching young people. Examining the decision making processes of media staff could facilitate a greater awareness of obstacles to portraying breast feeding and identify areas for intervention. The study of women's responses to media representations could inform future campaigns and interventions. It is important that clinicians, health educators, and policymakers are aware of patterns of media coverage and the complex cultural background within which women are making choices about infant feeding. The media may have profound implications for how women decide to feed their babies and thus for the health of the next generation.

Contributors: LH, the principal researcher on the project, formulated the study goals, gathered and analysed the data, and wrote the paper. JK formulated the study goals, analysed the data, and wrote the paper. JG formulated the study goals and provided expertise on infant feeding. Serena Patterson and Yvonne Wayne helped code the television programmes. LH and JK will act as guarantors for the paper.

Funding: The study "infant feeding in the media: an analysis of representation and influence" was funded by the Economic and Social Research Council (grant No R000222785).

Competing interests: None declared.

1 Chapman S, Lupton D. The fight for prublic health. London: BMJ Publishing, 1994

2 Begg N, Ramsay M, White J, Bozoky Z. Media dents confidence in MMR vaccine. $B M J 1999 \cdot 318: 30-4$

3 Grilli R, Freemantle N, Minozzi S, Domenighetti G, Finer D. Impact of mass media on health services utilisation. In: Cochrane Collaboration. Cochrane Library. Issue 2. Oxford: Update Software, 1999

4 Philo G. Media and mental distress. London: Longman, 1996.

5 Miller D, Kitzinger J, Williams K, Beharrell P. The circuit of mass communication: media strategies, representation and audience responses in the AIDS crisis. London: Sage, 1997.

6 Henderson L, Kitzinger J. The human drama of genes: 'hard' and 'soft' representations of breast cancer genetics. Sociol Health Illness 1999;21:560-78

7 Amos A, Bostock Y. Policy on cigarette advertising and coverage of smoking and health in European women's magazines. BMJ 1992:304:99-101.

8 Howie PW, Forsyth, JS, Ogston SA, Clark A, Florey CD. Protective effect of breastfeeding against infection. BMJ 1990;300:11-6.

9 Aniansson G, Alm B, Andersson B, Hikansson A, Larsson P, Nylen O, et al. A prospective cohort study on breast-feeding and otitis media in Swedish infants. Pediatr Infect Dis J 1994;13:183-8.

10 Pisacane A, Graziano L, Zona G. Breastfeeding and urinary tract infection. Lancet 1990;ii:336-50.

11 Ford RP, Taylor BJ, Mitchell EA, Enright SA, Stewart AW, Becroft DM, et al. Breastfeeding and the risk of sudden infant death syndrome, Int J Epidemiol 1993:22:885-90.

12 Mayer EJ, Hamman RF, Gay EC, Lezotte DC, Savitz DA, Kilngensmith GJ Reduced risk of IDDM among breast-fed children. The Colorado IDDM registry. Diabetes 1988;37:1625-32.

3 MacLean HM. Implications of a health promotion framework for research on breast feeding. Health Promotion 1989;3:355-60.

14 Hoddinott P, Pill R. Qualitative study of decisions about infant feeding among women in east end of London. BMJ 1999;318:30-4.

(Accepted 11 September 2000)

\section{Corrections and clarifications}

Comparison of intranasal midazolam with intravenous diazepam for treating febrile seizures in children:

prospective randomised study

A spelling error occurred in the references at the end of this paper by Eli Lahat and colleagues (8 July, pp 83-6). The name of the first author in reference 11 is Louon (not Lacon).

Global information flow

In the acknowledgment at the end of this editorial by Fiona Godlee and colleagues (30 September, pp 776-7), rather overzealous editing on our part led to an inaccuracy in the description of the Health Information Forum. The forum is an "activity" run as part of the INASP-Health programme and takes the form of a series of open themed meetings organised by INASP-Health.

ABC of breast diseases: Breast cancer-epidemiology, risk factors, and genetics

In this article by $\mathrm{K}$ McPherson and colleagues (9 September, pp 624-8) the fourth sentence of the final paragraph on page 627 should have started:

"The NSABP study randomised 13338 [not 3338] women with a risk equal to that of a 60 year old woman...." 